\title{
Exploring Factors Contributing to School Improvement in South African Secondary Schools in the Free State Province
}

\author{
T. M. Makoelle \\ Department of Educational Psychology, University of Johannesburg, South Africa, \\ P.O. Box 524, Auckland Park, Johannesburg 2006 South Africa \\ E-mail: tmakoelle@uj.ac.za
}

KEYWORDS Curriculum. Leadership. Management. School Effectiveness. Teaching

\begin{abstract}
Since the advent of the new educational dispensation in 1994, the South African National Department of education has embarked on a process of enhancing the improvement of pass-rates in secondary schools. However, despite these efforts the process has not been very smooth as some schools have not improved or least show signs of the improvement of their performances. This paper therefore explores factors contributing to school improvement in secondary schools. During this generative qualitative study data was collected from principals, SMT members, Teachers, and SGB member's focus groups. Face to face interviews were held with principals, focus group interviews were held with school management teams, teachers and school governing body parents. Documentary analysis from three highly improved schools (those that have seen dramatic improvement in learner attainment and basic functionality over three years) and three less improved schools (those that have not improved their learner attainment and basic functionality over three years) was also done. Data was then analysed using constant comparative analysis within an inductive analytical framework. Among the findings of the study is that management and leadership, effective curriculum management, effective school governance and an effective support structures are at the heart of any school improvement success.
\end{abstract}

\section{INTRODUCTION}

School improvement as opposed to school effectiveness is the process by which school attempt to improve their effectiveness, which means their learner attainment output and basic functionality. School effectiveness on the other hand is when the school can efficiently achieve goals it has set for itself (Makoelle 2012). So school effectiveness is largely a product of school improvement process (Makoelle 2012). School improvement in this study is understood to mean an ongoing process by which the school strives for high level of productivity and effectiveness in terms of learner attainment. In the past, school improvement in South Africa was driven by NGO projects funded by corporate and international donors. After 1994, a multiplicity of projects were initiated and driven by the government; hence, the current literature on school improvement in South Africa is dominated by various projects that the Department of Education has implemented to effect improvement at schools (Taylor in Townsend 2007), for example: The Imbewu Project (1998-2001) in the Eastern Cape at 523 rural schools. From 1994 2003, standards-based accountability was used when matriculation results declined. Improve- ment plans were designed to change the situation at dysfunctional schools (schools attaining less than a $20 \%$ matriculation pass rate). Several projects were also implemented to align curriculum, teaching and assessment. These included for example: The District Development and Support Project (DDSP) from 2000-2002 at 453 primary schools (in rural areas) focused on improving the functionality of districts and schools.

Furthermore, COLTS (Culture of Learning and Teaching Services) campaign was instituted by the South African Government to resuscitate the schools from the breakdown of the culture of teaching and learning as a result of the revolution against the Bantu Education Act (Rampa 2005). COLTS was a presidential project initiated in 1996. According to Rampa (2005), it was integrated as an improvement strategy with two other strategies, namely Total Quality Management (TQM) and TIRISANO (the latter word means 'working together'), which sought to transform the institutional cultures of schools into those of collaboration and team building. Rampa (2005) indicates that, despite the project, school productivity remained low, which was a sign that improvement as a result of the implementation of the project did not succeed. 
Following COLTS, a number of projects were initiated to improve the quality of teaching and learning at schools; for example Kanjee (2005) and Taylor and Prinsloo (2005) indicate that the improvement intervention called the Quality Learning Project (QLP) was initiated to improve the conditions at secondary schools spread across the nine provinces. This project was sponsored by the Business Trust and the National Department of Education and was managed by Jet Education Services with its interventions predominantly managed by NGOs.

The QLP improvement strategy was based on a systemic model, which involved intervention at district, school and classroom level to improve the conditions at schools with less capacity to promote effective teaching and learning. QLP activities were geared towards the improvement of the following: teaching of mathematics, reading and writing skills at 524 schools; governance and management of schools and management in 17 districts. In a similar vein, the Dinaledi Project, which was intended to improve the teaching of Physical Science and Mathematics, was implemented at 102 schools. While the outcome of the Dinaledi Project was slightly better than that of the QLP, the overall improvement was not significantly high (Taylor and Prinsloo 2005).

Coupled with these processes, there were attempts to change management approaches to improve schools (Madasi 2004); to capacitate management and leadership (Hoadley et al. 2009) and to conduct several studies on how schools could be improved, for example the influence of School-Based Management (SBM) which is a system advocating a decentralisation of powers to allow the school leader to take decisions that could influence the improvement of their schools (Botha 2002, 2004).

There have also been efforts to develop comprehensive improvement plans that can complement both systemic and management dimensions; for example, the Eastern Cape Member of the Executive Council (MEC) of Education has adopted an improvement strategy called Master Plan 2010 (DoBE 2010). This plan focuses on the systemic, management and resource needs of schools in that province for improvement to take place, which reflects a holistic or comprehensive approach to school improvement. Lately, The Minister of Basic Education, Ms Angie Motshekga, has announced that the recently formed National Education Evaluation and Development Unit (NEEDU) which will monitor the administration of tests on numeracy and literacy to Grades 3, 6 and 9 (Govender 2010). This is seen as a move to raise standards and enhance improvement as far as the quality of teaching and learning is concerned. However, this raising of standards has become problematic. Furthermore, DoBE in 2008 and 2009 has launched the QLTC, which is partly funded by the Education and Labour Relations Council (ELRC). It has secured a long-term commitment from different stakeholders - including teachers' unions, school-governing-body organisations, and learner organisations - to work together to improve the quality of education (Davies 2010). The current situation is that the QLTC has not filtered through to the grassroots (that is many schools have not yet understood and implemented the campaign fully). Jansen (2004) postulates that the improvement of the culture of learning at schools is hampered by the deeply held convictions and perceptions by teachers that evaluation of their work could result in victimisation.

While other improvement strategies such as those discussed above focused on systemic aspects of education to improve teaching and learning, others targeted the development of management and leadership to effect improvement. The above initiatives were attempts to enhance school improvement, meaning to increase their learner attainment and basic functionality. The analysis of the projects discussed earlier shows that very little improvement was actually registered at schools as some schools continued to underperform. In 2009 matriculation results recorded a decline of $2 \%$. Since then, in an attempt to rectify the situation, the Minister of Basic Education has made several statements to the effect that education in schools has to be improved as a matter of urgency (Davies 2010). In 2012 the matriculation results improved but other provinces registered a decline in the pass rates. The observation is that various projects that were put in place to improve schools have not been necessarily successful. Be that as it may, it can also be noted that other schools within this improvement initiatives were able to improve their learner attainment and basic functionality while other did not. Therefore it is import to explore which factors contribute to school improvement. 
Therefore the following research question was posed:

Which factors contribute to improvement of South African secondary schools?

\section{Conceptualising School Improvement and Change}

Teddlie and Reynolds (2000: 146) define school improvement as the 'long-term goal of moving towards the ideal type of the self-renewing school'. Schools improve as they embrace the spirit of change; and change from the current to the future state depends on how well change is managed at a school. Hopkins (1987: 57) defines school improvement as:

... a sustained effort aimed at change in learning conditions and other related internal conditions in one or more schools, with the ultimate aim of accomplishing educational goals more effectively.

The preceding statement focuses attention on school improvement as a process characterised by change. Therefore, there is an important link between change and school improvement (Lukacs and Galluzzo 2014). According to Hopkins (2001), change plays a pivotal role in school improvement as schools adapt their internal conditions in response to change, which may lead to school improvement.

School improvement seem to revolve around the phenomenon of change as a prerequisite for improvement.

Some schools fail to improve because the process of change is not properly planned, initiated, implemented and monitored. Harris et al. (1997) compare a school to a system with components that are dependent on one another for the system to function. The authors indicate that change initiated from the bottom up is more sustainable than from the top down, because those for whom change is intended are involved, a position shared by Mills (1990) and echoed by Lukacs and Galluzzo (2014). Macbeath and Mortimore (2001: 153-154) argue that change towards school improvement may be realised if a profile of change is developed to guide areas which need improvement.

School improvement is determined by specific aspects stemming from management, curriculum and school to social issues. Fullan (2004) like Caputo and Rastelli (2014) argues that the reason why most schools struggle to improve is that change is often difficult to implement. Fullan $(1999,2001)$ further points out that schools are places characterised by diversity, power relations and micro-politics, which often complicates the transition from the current state of affairs to the improved one.

Fullan (1999) furthermore states that change should be a priority need for the school community, with a clear set of objectives and goals, monitored and carefully planned. Change is often disturbed when there is an autocratic leadership style that prohibits free engagement by those at whom change is directed (Engelbrecht and Green 2001; Weber 2007). The relevance of change as a contributory variable to school improvement seems to lie in how it is approached. Change is a component of school management and leadership; therefore, the way change is approached may have a profound influence on school improvement. However, the management approaches, as well as the leadership and management philosophy at a school, seem to diverge because of the varied contexts and prevailing conditions.

\section{Some Approaches to School Change and Improvement}

Change and improvement usually begin with the process of initiation. Change is then implemented and institutionalised to become part of the school culture. Coppieters (2005) warns that a school is a complex, unpredictable and dynamic institution. Improvement depends on how well change is managed and how well the school is transformed into an institution of learning. School improvement is guided by the processes of goal-setting, pressure and need to improve, cyclical improvement processes, and school autonomy (Scheerens and Demeuse 2005).

Change and improvement are core concepts in all definitions of leadership. School improvement is about capacitating school leaders to improve on the service provided to learners. There is a strong relationship between leadership and change. School leaders need change to effect improvement at their institutions. The quality of change is often determined by the extent to which it affects the improvement of the school. The school leader is charged with the responsibility of implementing change through various approaches. While there are many theories of change in the literature, the complexity and evo- 
lutionary change theory of Michael Fullan is relevant and appropriate. Fullan (1999: 36) distinguishes between two approaches of educational change, namely the complexity approach and the evolutionary approach. The complexity approach is a more interactive approach towards change whereby stakeholders interact to bring about a state of stability. By contrast, the evolutionary approach assumes that change will happen over time.

The choice of either approach to change will depend on the circumstances and the context within which change takes place. The school culture of management, learning, assessment and routine can all have a profound effect on how successfully change is implemented. School improvement signifies a change from the current to the new state (Fullan 2004).

Writing in support of the complexity approach, Mittler (2000: 134) postulates that change is an ongoing process, and that for change to be successfully implemented, all those involved should continually monitor and reflect on the process (McCallion 1998; Loreman et al. 2005). Those involved in change should continually challenge their beliefs and notions about the process of change (Goodson 2003). Similarly, Richards et al. (2001), Haney et al. 2002) argue that beliefs, attitudes, knowledge and understanding are pivotal points to be looked at closely if any success is to be registered.

The complexity approach to change is congruent with the notion of collaboration advanced by Mohr et al. (2004), Richardson (1998), Somekh (2006), and Ainscow et al. (2006). This notion is crucial for the successful implementation of change as those for whom change is intended collaborate to bring about improvement to their practice. To bring about the desired results, reflection is crucial for educational change, challenging the status quo and introducing new ideas (Fullan and Hargreaves 2002; Briscow 1996; McTaggard 1997; Hoban 2002).

Collaboration with the school community will develop into what Fullan (2001) calls a professional learning community. The community affords stakeholders the opportunity to learn together in what will be referred to as a community of practice (Wenger 1998; Hargreaves 1997; Fullan 2001). A community of practice should probe its own practices with a view to improving them (Reason and Bradbury 2006; Retallic et al. 1999). The approaches to change and school improve- ment often orientate and direct the type of the strategy the school will adopt in enhancing improvement. The following section briefly looks at some examples of such strategies.

\section{Strategies of School Improvement}

A number of strategies are applied in an attempt to improve schools, but essentially there are two main perspectives in this regard: firstly, there is the belief that the school can improve when an outside body determines what standards the school should meet (for example, setting targets and benchmarks); secondly, it is believed that the school should continually review its progress and performance for service to improve - hence the notion of the learning school. McGilchrist et al. (1997), Senge et al. (2000), and Sun et al. (2007) highlight the significance of a school's continual learning process about itself to bring about improved performance. This learning process is embedded in the school, clearly articulating its vision, embarking on continual staff development, good leadership, fostering learning on behalf of the school community, and enhancing community networks.

The school learns through the process of school-development planning. Hargreaves and Hopkins (1991: 3, 1994) believe that a school learns by continually planning its development. They define school-development planning as the process of planning the improvement and then implementing the plans over a specified period. School- development planning must encompass the performance indicators that will make it easy for the progress to be monitored (Hulpia and Valcke 2004). The continual cyclic procedure of school-development planning allows the school continually to reflect on its improvement initiatives and plan for future improvement. This according to Hargreaves and Hopkins (1991) include audit, construction, implementation and evaluation. Hargreaves and Hopkins (1991) indicate that school-development planning is not linear but circular: one process leads to the next; for example, construction leads to implementation. School-development planning is usually a collective effort on the part of the stakeholders at the school. It is a never-ending process aimed at achieving the vision of the school.

Total Quality Management (TQM) is another improvement strategy suggested by Harris et 
al. (1997: 263-268) and Motaboli (2009) who posit that improvement takes place in a cyclical process called TQM (Total Quality Management) defined as 'continuously meeting agreed customer requirements at lowest cost'. TQM is a management approach geared towards developing an educational institution in totality and achieving school improvement and effectiveness. TQM groups employees together, identifies opportunities for improvement, and engages in problem-solving. It focuses on goal attainment by the school and looks at how well the school is adapted to its routine. It is important that there is a clear focus on the internal conditions of the school, clear decisions about development and maintenance, and that external change is adapted for internal purposes. Improvement should cut across all levels. Performance data should be used to plan future development, and change should be accepted to transform school culture. TQM looks at the operation of the school in its wholeness, and it is furthermore related to strategic management.

Middlewood and Lumby (1998) reflect on and single out strategic management within TQM as the component that enhances the chances of improving efficiency and effectiveness. The authors believe that being proactive and planning ahead strategically enhances the quality of planning and therefore results in quality work. The authors define strategic management as an approach to managing with anticipation, and providing for the unexpected in the process of enhancing improvement. Strategic thinking is an important step that all school managers should embark on.

Strategic management has to develop a vision (image of what might be) and mission (how to achieve the vision) and set clear objectives (Knight 2014). This could take place in an organisational culture that is geared towards improvement. The phenomenon of strategic management is geared towards ensuring that the school is self-managing. Schools come to be selfmanaging when all activities are carefully planned and carried out (Caldwell and Spinks (1998). The concept self-managing school is closely linked to the process articulating the decentralisation of powers to schools, which is the notion of School-Based Management (SBM) (Nenyod 2002).

The implication seems to be that, in relative terms, self-managing schools strive to improve their current state. While noting the impact of school-development planning, TQM, SBM, and strategic management on school improvement, Visscher and Coe (2002) highlight on the one hand, how the use of external feedback by performance feedback systems can influence school improvement. External evaluation is believed to be providing a clearer understanding from a distance. Conversely, there are those who believe that change and improvement can only come about if schools work together. Waghid (2002: 2) uses the term deliberate schooling, implying an emphasis on deliberation, aiming to deepen, institutionalise, facilitate, consolidate and develop cooperation and participation in all schools. Such cooperation is necessary, especially between formerly advantaged and disadvantaged schools in South Africa. The notion of Waghid's deliberate schooling seems to get close to the process of mentoring by definition.

Love (1993) postulates that mentoring is one of the systems known to enhance the improvement of organisations such as the school. The functions of the mentor are usually to provide support to protégés through coaching and assigning tasks that will lead to the development of the protégé. The mentor should act as a role model of positive attitudes, beliefs and values. The mentor should facilitate discussions about the protégé's work and dispel the protégé's anxieties and fears. Teachers at all levels of management at school could be mentored for the enhancement of their performance and therefore school performance.

Although school improvement is an ongoing process, evaluating or measuring it is critical as it relates to how effective change has been. Two views of ensuring school improvement prevail, namely, that of using learner attainment as a yardstick and that of using whole-school evaluation with specific indicators of change or improvement. Scollay and Everson (1985) warn against using student achievement as the sole criterion to evaluate school improvement. On the other hand, Crowley and Hauser (2007), while advocating the approach of whole-school evaluation to measure school improvement, believe that the evaluating strategies need ongoing conversations about the nature of evidence and elements of the research practice.

\section{METHODOLOGY}

Qualitative research is intended principally to interrogate both the research process and the end-product of the research. It differs from the quantitative approach in that the process is not 
aimed at the generalisation of findings but focuses on achieving a deeper understanding of the phenomenon being studied. The data collected qualitatively are tacit (intuitive) and their reliability and validity depend on what Lincoln and Guba (1985) call 'trustworthiness' (Cresswell 2003: 186). While some researchers often regard qualitative and quantitative research approaches as competing paradigms, researchers such as Cresswell (2003) view them as mutually complementary to the research process. This study, however, used a qualitative research approach because it allowed the study to be conducted in natural settings, where the perceptions and experiences of the researcher and the researched could be taken into consideration for the purposes of understanding and describing the data (Motaboli 2009). In linking the casestudy method with qualitative research, Noor (2008) describes the case-study method as a strategic qualitative method. The relationship between the qualitative research approach and case study mostly stems from the need to generate a deeper understanding of the phenomenon and to take the perceptions and experiences of research subjects into consideration. The goal of the case-study method is therefore to generate meanings to understand the phenomenon being studied (Noor 2008).

The case-study method is in many instances used together with the qualitative research approach, because the phenomenon is studied in a real-life context. Case studies are mostly concerned with why and how things happen, clarifying the difference between the contexts of what was planned and what actually happened during an inquiry. This leads to an in-depth understanding of the phenomenon (Yin 2003; Noor 2008).

\section{Population and Sampling}

Population is defined by Neuman (2006: 224) as the abstract idea of a large group of cases from which a researcher draws a sample from which results are generalised. Sapsford (2007) adds that population means the entire set of objects spoken about and about which generalisations are made. The population in this study therefore comprises all secondary schools in the Free State Province, their principals, school management teams, teachers, and school governing body parents.
Sample is defined by Neuman (2006: 218) as a small set of cases a researcher selects from a larger pool and generalises to the population. For logistical reasons, such as resources and time, only six secondary schools in a selected district of the Free State Province were selected to constitute a sample. The schools in the district were selected purposefully, which means that a sample was constituted according to the availability of subjects rather than on the basis of representativeness (Leedy 1993).

The sample comprised of three highly improved schools and three less improved schools in terms of learner achievement. Leaner attainment was the only indicator of improvement used as it was easy to make comparisons over a three year period. Documentary analyses of the six schools were done. The sampling of schools was done in a random manner, using a quotasampling technique. Neuman (2006: 220) describes quota sampling as:

getting a preset number of each of several predetermined categories that will reflect the diversity of the population using haphazard method.

Stringer (2008) and Sapsford (2007) support this definition of quota sampling. Three highly improved schools and three less improved schools were selected on the basis of their matriculation results. Schools which improved their learner attainment from $60 \%$ to more than $80 \%$ pass rate were regarded as highly improved and schools which consistently attained a less than $60 \%$ pass rate in three years as less improved schools. The $60 \%$ and $80 \%$ bench-marks were used as a distinguishing factor to highly improved and less improved schools given the Free State provincial average in pass-rates. While these thresholds were used for determining the level of improvement in the Free State Province, caution should be exercised as $60 \%$ could be regarded as highly improved in other provinces or in other contexts. The results used were culled from the years 2010, 2011 and 2012. The data was received from the six schools are summarized in Table 1.

Table 1: Summary of participants

\begin{tabular}{llc}
\hline Participants & Place & Number \\
\hline Principals & Schools & 6 \\
SGB focus group (Parents) & Schools & 6 \\
School-management team & Schools & 6 \\
focus group & Schools & 6 \\
\hline
\end{tabular}




\section{Data Collection}

The semi-structured interview is a personto-person conversation with the objective of exploring the research topic with the research participant (Watts and Ebbutt 1987; Trochim 2001; Bryman 2001; Burton 2000; Yates 2004; Cresswell 2003; Wengraf 2001). One-on-one interviews with principals and school-based focus-group interviews were the first phase in the qualitative phase. During this phase, six (6) semistructured interviews were conducted with each of the six principals of the selected schools $(1 \times 6=6)$.

According to Babbie (2004: 302), a focus group is 'a group of 12 to 15 people brought together in a room to engage in a guided discussion about some topic'. The same definition is supported by Wong (2008), Krueger (1994), Laws et al. (2003), Kelly (1998) and Wilson (1997). Focus-group interviews with three different focus groups, also purposefully sampled, consisted of six SMT members, six SGB members and six teachers from each school followed.

\section{Data Analysis}

The analysis of qualitative data, according to Blaikie (2000), therefore takes into consideration the views of participants and the process and context. According to Mouton and Marais (1993), the aim of data analysis is to understand the components of data and determine the relationship between variables, patterns and themes. Data analysis results in interpretation, which involves synthesising data into a coherent whole.

The researcher attempted to make sense of all the data collected qualitatively; that is, from unstructured interviews, SGB focus-group interviews, and documentary analysis. The researcher used a systematic set of procedures to develop and inductively derive theory about the phenomenon, a principle borrowed from grounded theory (Strauss and Corbin 1990: 24). The developmental data analysis was characterised by the following series of basic steps (Laws et al. 2003: 395):

- Step 1: Reading and rereading all the collected data

Reading the data ensured that the researcher was familiar with the data, thus making the process of analysis much easier and more manageable.
- Step 2: Making a preliminary list of themes arising from the data

The process of categorising data into themes, referred to as 'coding', has been conceptualised by Miles and Huberman (1994) as labels or texts assigned to units of meaning of pieces of data collected. Similarly, Neuman (1997) refers to the process as organising raw data into conceptual categories in order to create themes that will be used to analyse the data. Consequently, the data were categorised into themes.

- Step 3: Reading the data again to confirm the themes

It is crucial that data be studied several times to verify that the interpretations are correct and valid. The data were read several times to confirm the themes.

- Step 4: Linking themes to quotations and notes

The researcher then wrote themes next to the quotations and notes while examining the data.

- Step 5: Examining and interpreting the categories of themes

From the meaning attached to the interpretations of themes, logical conclusions were drawn.

\section{FINDINGS}

The analysis of data presented five themes which seemed instrumental for school improvement:

\section{Theme: Management, Leadership and Administration}

The analysis of data seems to suggest that at in highly improved schools, improvement is incorporated into the vision, mission and School Development planning. For example one of the principals from highly improved schools had this to say "our vision and mission strive for sustainable improvement and maintaining and improve our current levels of effectiveness" While at less improved schools the above-mentioned aspects were not prioritised. There seems also to be an indication that in highly improved schools performance of the school are reviewed annually in relation to the targets set for particular academic year. For example one SMT member of highly improved school postulated "we have annual performance targets so, we review our performances frequently to determine whe- 
ther we have achieved what we have set for ourselves" While at less performing school there review of performance is infrequent and non aligned to the overall improvement target of the school.

There is an indication of visible leadership and show of leadership's willingness to improve through actions enhances the drive to improve performance in highly improved schools conversely the leadership in less improved school seem invisible and take less action-based initiative about the improvement of performance, in support of this it was clear in the following extract from the principal of a highly performing school “I apply management by wondering about, I am not office bound, as principal if you want improvement it has to start with you" Highly improved schools seem to prioritise the allocation of resources, especially funds into programmes that enhance school improvement. For instance one of the principal has this to say " it is important to allocate resources to areas that will impact highly on teaching and learning as those are the core business of improvement and performance" The indication in less improved schools is that resources are not necessarily prioritised for improvement but follow a normal resource allocation process.

\section{Theme: Learner Related Factors}

Highly improved schools seem to have a robust and clear programme of learner motivation which seems learners highly motivated to perform. This was attested by one of the SMT members who articulated "the improvement of learner performance is influenced by our willingness to keep all learners motivated, we invite key motivational speakers and our previous successful learners to share their success stories with our current learners" On the other hand, less improved schools do not regularly motivate learners there is a attitude of finding excuses of non-performance by learners. Clear support structures for learners with special educational needs seem well functioning in highly improved schools while at less improved school there inadequate support and poorly functioning support structures. For instance one principal from the highly improved school indicated "we identify learners that are at risk of failure early and we device intervention programmes to support them" Highly improved schools re- ward good performance, regular functions seem to be organised to recognise good performance which is not the case in less improved schools. One of the principals from highly improved schools indicated "we are a school were excellent performance is recognised at our well done functions and in class by teachers"

\section{Theme: Teacher and Teaching Related Factors}

Teachers in highly improved schools exhibit high levels of motivation as compared to the counterparts in less improved schools. As evidence the following quote is illustrative "our teachers are in time, in class and teaching, they are not to be watched or be told to do their work, they have a sense of accountability and are driven" There seem to be high level of planning and preparation for teaching in highly improved schools which seem not to be the case in less performing schools. For example one of the SMT members indicated "teachers in my department are always prepared for class and their planning reflects lessons for the whole academic year and there is quality in lesson planning" Work is regularly monitored and controlled in highly improved schools and appropriate interventions are done timely, such that improvement is not hindered. To support this one principal said "it is important that from time to time you check the level of quality because that will impact on the performance of the entire school"

\section{Theme: School Governance Factors}

School governing bodies of highly improved schools seem to prioritise performance in a sense that parents are regarded as partner so are urged regularly to support their learners and be vigilant of poor performance on part of learners and report such to school authorities such that appropriate measures are implemented to deal with non performance, such does not happen in less improved schools. For instance one SGB member of one the highly improved school attested "we have performance targets, which keep us performance driven, for instance our parents are encouraged to motivate their learners to perform and excel in school work." There seem to be a strong emphasis on learner participation in sport and other extra-curricular activities and exercising is highly cherished, while in less im- 
proved schools, sport and other extra-curricular activities, seemed as though they are not highly prioritised. For instance the SGB member of highly improved school alluded "we believe that when children participate in sport their health in kept intact therefore their academic performances stay high"

\section{Theme: Support Structures Related Factors}

The indication in highly improved schools is that external support is outsourced if certain subjects are not improving on pass-rates while in less improved schools this is not common practice. Learners are subsidised to attend enrichment programmes organised by both private and governmental organisation with the aim to improve performances. This was supported by the following extract by the principal of highly improved school "We hold camps during school holidays and we get best teachers especially in science subjects and this enrichment activities impacts positively on performances of our learners."

\section{Theme: Change Related Factors}

The indication was that in high improved school all stakeholders seemed to embrace the fact that the current conditions of school performance needs to change for the better. Stakeholders were more willing to change and improve the way thing are done which was not the case in less improved schools which seem to be rigged by conflict. For instance one of the SMT member of the highly improved school said "our school improve and do well because we all want better performance for our school, it is a collaborative effort." This statement also seemed to suggest that an improvement initiative derived from within the school has more impact than the one initiated from outside the school as stakeholders tend to own the process.

\section{DISCUSSION}

The study indicated that the school that has visible and effective school management and leadership create a fertile ground for school improvement (Macbeath and Mortimore 2001; Yang 2014), this according to the study is that improvement must be encapsulated into vision and mission of the school and the management and leadership of the school must embrace, im- plement and monitor an improvement process by reviewing performance regularly (Hopkins 1991; Hulpia and Valcke 2004; Makoelle 2012). The study has shown that improving schools invest their resources in their improvement activities. It is also clear from the study that motivation of learners, recognition of good performance and clear learner support structures for learners with special needs are pivotal for school improvement (Makoelle 2012). Further visionary governance geared towards parental involvement in both curricular and extra-curricular activities is very instrumental and that a balance between extra-curricular activities with teaching and learning was significant in creating a conducive atmosphere for school improvement (Makoelle 2012). The study has indicated that improvement of a school is enhanced by motivated teachers, prepared for teaching task and whom their work is regularly controlled (Fullan 1991; Weber 2007; Hallinger et al. 2014). The study has indicated that school improvement was linked to how well leadership, teachers and other stakeholders were willing to change from the current state to the new state, thus improving the performance of the school (Fullan 1999; McGilchrist et al. (1997), Senge et al. (2000), and Sun et al. (2007). This has also highlighted the significance of collaboration among all stakeholders in spearheading school improvement (Reason and Bradbury 2006; Retallic et al. 1999). It is important to realize that school improvement initiative are likely to success when initiated internally by the school a notion contrary to external intervention (Lukacs and Galluzzo 2014).

\section{CONCLUSION}

While it will be ambitious to claim that factors revealed in this study are the only ones contributing to school improvement, it suffices to argue that they are significant in enhancing school improvement. The study therefore has constituted a contribution into knowledge about school improvement in South Africa or countries with similar contexts. The study makes valuable input into how school improvement could be enhanced in South African schools.

\section{RECOMMENDATIONS}

It is therefore recommended that school leadership and management infuse the improvement 
objectives in the school development planning and continuously monitor regularly progress towards their targets. Schools should continuously motivate both learners and teachers and advocate in their activities the drive to improve the performance of the school. It also suffices to recommend that school governing bodies be involved in setting improvement targets for the school and that school put in place clear learner support structures to deal with the need to intervene when necessary. Schools must endeavour to motivate teachers and prepare them thoroughly for their improvement initiatives. Change in schools is central to school improvement and both leadership and stakeholders need to embrace the envisioned improvement targets. Stakeholder collaboration needs to be facilitated as this provide for a coherent effort for school improvement.

\section{REFERENCES}

Ainscow M, Booth T, Dyson A 2006. Improving Schools: Developing Inclusion. London: Routledge.

Babbie E 2004. The Practice of Social Research. Belmont: Thomson Wadsworth.

Blaikie N 2000. Designing Social Research. Oxford: Blackwell Publishing Ltd.

Botha RJ 2004. Excellence in leadership: Demands on the professional school principal. South African Journal of Education, 24(3): 239-243.

Botha RJ 2006. Leadership in school-based management: A case study in selected South African schools. Journal of Education, 26(3): 341-353.

Briscoe C 1996. The teacher as learner interpretations from a case study of teacher change. Journal of Curriculum Studies, 28(3): 315-329.

Bryman A 2001. Social Research Methods. Oxford: Oxford University Press.

BurtonDC 2000. Research Training for Social Scientists. London: Sage Publications.

Caldwell BJ, Spinks JM 1998. Beyond the Self-managing School. London: Routledge.

Caputo A, Rastelli V 2014. School improvement plans and student achievement: Preliminary evidence from the quality and merit project in Italy. Improving Schools, 17(1): 72-98.

Coppieters P 2005. Turning schools into learning organizations. European Journal of Teacher Education, 28(2): 129-139.

Cresswell JW 2003. Research Design: Qualitative, Quantitative and Mixed Methods Approaches. $2^{\text {nd }}$ Edition. London: Sage Publications.

Crowley JJ, Hauser H G 2007. Evaluating whole school improvement models: Creating a meaningful and reasonable standards review. Journal of Education for Students Placed at Risk, 12(1): 37-58.

Davies B 2010. The state of education in South Africa. The New Negotiator, ELRC, 3(3): 1-8.
DoE 2010. Statement by the Minister of Basic Education, Mrs A Motshekga, MP, on the Announcement of National Senior Certificate Grade 12 Examination results for 2009. Media Centre, Union Building, 07 January 2010.

Engelbrecht P, Green L 2001. Promoting Learner Development: Preventing and Working with Barriers to Learning. Pretoria: Van Schaik Publishers

Fullan M 1999. Change Forces: The Sequel. London: Open University Press.

Fullan M 2001. The New Meaning of Educational Change. $3^{\text {rd }}$ Edition. London: Routledge Falmer.

Fullan M 2004. Leading in a Culture of Change: Personal Action Guide and Workbook. San Francisco: Jossey-Bass.

Goodson IF 2003. Professional Knowledge, Professional Lives:Studies in Education and Change. Philadelphia: Open University press.

Govender P 2010. New National Exams for SA School Kids: Grade 3, 6 and 9 Write Common Exams. Sunday Times, 5 September: 14.

Fullan M, Hargreaves A 2005 Teacher Development and Educational Change. London: Routledge Falmer.

Hallinger P, Heck R H, Murphy J 2014. Teacher evaluation and school improvement: An analysis of the evidence. Educational Assessment, Evaluation and Accountability, 26: 5-28

Haney J J, Lumpe A T, Czerniak C M, Egan V 2002. From beliefs to actions: The beliefs and actions of teachers implementing change? Journal of Science Teacher Education, 13: 171-187.

Hargreaves RE 1997. Beyond Educational Reform: Bringing Teachers back in. Buckingham: Open University Press.

Hargeaves DH, Hopkins D 1991.The Empowered School: The Management and Practice of Development Planning. London: Cassel.

Harris A, Bennet N, Preedy M 1997. Organizational Effectiveness and Improvement in Education. Buckingham: Open University Press.

Hoadley U, Christie P, Ward CL 2009. Managing to learn: Instructional leadership in South African Secondary Schools. School Leadership and Management, 29(4): 373-389.

Hoban GF 2002. Teacher Learning for Educational Change: A System Thinking Approach. Buckingham: Open University Press.

Hopkins D 1987. Improving the Quality of Schooling: Lessons from the OECD International School Improvement Project. London: Falmer Press.

Hopkins D 2001 The Past, Present, and Future of School Improvement towards the Third Age, Volume 27, Issue 4: 459-475.

Hulpia H, Valcke M 2004. Use of performance indicators in a school improvement. Evaluation and Research in Education, 18(2): 102-119.

Jansen JD 2004. Autonomy and accountability in the regulation of the teaching profession: A South African case study. Research Papers in Education, 19(1): 51-66.

Kanjee A 2005. Methodological Challenges in Evaluating Large Scale Intervention Programs: Reflections from the Quality Learning Project. Biennial Psychological Conference on Research in Psycholo- 
gy and Related Disciplines. University of Johannesburg: 7-8 July.

Kelly B 1998. The Handbook for Focus Group Research. $2^{\text {nd }}$ Edition. London: Sage Publications.

Krueger N 1994. Focus Groups: A Practical Guide for Applied Research. $2^{\text {nd }}$ Edition. London: Sage Publications.

Laws S, Harper C, Marcus R 2003. Research for Development. London: Sage Publications.

Leedy D 1993. Practical Research: Planning and Design. $5^{\text {th }}$ Edition. New York: Macmillan Publishing Company.

Lincoln YS, Guba EG 1985. Naturalistic Inquiry. London: Sage Publications.

Loreman T, Deppeler J, Harvey D 2005. Inclusive Education: A Practical Guide to Supporting Diversity in the Classroom. London: Routledge Falmer.

Love LM 1993. Managerial Career Development through Mentoring: Conditions for Effective Formal Mentoring Programmes. MSc Dissertation, Unpublished. Manchester, UK: University of Manchester.

Knight J 2014. Strategic Planning for School Managers. London: Routledge.

Lukacs K S, Galluzzo G R 2014. Beyond empty vessels and bridges: Toward defining teachers as the agents of school change. Teacher Development, 18(1): 100-106.

Macbeath J, Mortimore P 2001. Improving Schools' Effectiveness. Philadelphia: Open University Press.

Madasi V 2004. Secondary School Principals’ Perceptions and Experiences of Management Developmental Programmes. MEd Thesis. Grahamstown: Rhodes University.

Makoelle TM 2012. School Effectiveness and Improvement in South Africa. Saarbrücken: Lambert Academic Publishing.

McCallion P 1998. Achievement for All: Achieving Excellence in Schools. London: Stationary Office.

McGilchrist B, Myers K, Reed J 1997. The Intelligent School. London: Sage Publication.

McTaggard R 1997. Participatory Action Research. New York: State University of New York Press.

Middlewood D, Lumby JC 1998. Strategic Management in Schools and Colleges. London: Paul Chapman Publishers.

Miles BM, Huberman AM 1994. Qualitative Data Analysis: An Expanded Sourcebook. $2^{\text {nd }}$ Edition. London: Sage Publications.

Mills GE 1990. A Consumer's Guide to School Improvement: Trends and Issues Series. Eugene: Eric Clearinghouse on Educational Management.

Mittler P 2000. Working Towards Inclusive Education: Social Context. London: David Fulton Publishers.

Mohr MM, Roger C, Sanford B, Nicerino MA, Maclean MS, Clawson S 2004. Teacher Research for Better Schools. New York: Teacher College Press.

Motaboli T 2009.Curriculum 2005 (C2005/NCS), Outcomes Based Education (OBE) in South Africa: Instructional Difficulties, Curriculation and Quality Assurance. Lesotho: Morija Printing Works.

Mouton J, Marais, HC 1993. Basic Concepts in the Methodology of the Social Sciences. Pretoria: Human Science Research Council.
Nenyod B 2002. School-based Management: Thai Ways and Methods. National Pilot Study: Learning Reform Schools for Developing Quality of Learners. Thailand: Office of the National Education Commission.

Neuman WL 1997. Social Research Methods: Qualitative and Quantitative Approaches. Boston: Allyn and Bacon.

Neuman WL 2006. Social Research Methods: Qualitative and Quantitative Approaches. $6^{\text {th }}$ Edition. Munich: Pearson.

Noor, KBM. 2008. Case study: A strategic research methodology. American Journal of Applied Sciences 5(11): 1602-1604.

Rampa SH 2005. The Relationship between Total Quality Management and School Improvement. PhD Thesis. Pretoria: University of Pretoria.

Reason P, Bradbury H 2006. Handbook of Action Research. London: Sage Publications.

Retallick K Cocklin B, Coombe K 1999. Learning Communities in Education. London: Routledge.

Richards JC, Gallo PB, Renadya WA 2001. Exploring teacher's beliefs and the process of change. The PAC Journal, 1(1): 1-17.

Richardson V 1998. How teachers change. Focus on Basics, 2(c) September: 1.

Sapsford R 2007. Survey Research. London: Sage Publications.

Scheerens J, Demeuse M 2005.The theoretical basis of the effective school improvement. School Effectiveness and School Improvement, 16(2): 375-385.

Scollay SJ, Everson ST 1985. Measuring school improvement: A few experientially-based words of caution. Urban Review, 17(3): 201-209.

Senge P, Cambron-McCabe N, Lucas T, Smith B, Dutto J, Kleiner A 2000. Schools that Learn: A Fifth Discipline Fieldwork for Educators, Parents and Everyone Who Cares About Education. London: Nicholas Brealey Publishing.

Somekh B 2006. Action Research: A Methodology for Change and Development. Maidenhead: Open University Press.

Strauss A, Corbin J 1990. Basics of Qualitative Research: Grounded Theory Procedures and Techniques. London: Sage Publications.

Stringer E 2008. Action Research in Education. New Jersey: Pearson Merril Prentice Hall.

Sun H, Creemers B, Bert PM, De Jong R 2007.Contextual Factors and Effective School Improvement, 8(1): 93-122.

Taylor N, Prinsloo C 2005. The Quality Learning Project: Lessons for High School Improvement in South Africa. Johannesburg: Jet Education Services.

Teddlie C, Reynolds D 2000. The International Handbook of School Effectiveness Research. London: Falmer Press, Taylor and Francis Group.

Townsend T 2007. International Handbook of School Effectiveness and Improvement. Dordrecht: Springer.

Trochim WMK 2001. Research Methods: Knowledge Base. Cincinnati: Atomicdog Publishing.com.

Visscher AJ, Coe R 2002. School Improvement through Performance Feedback. Lisse: Swets and Zeitlinger Publishers.

Waghid Y 2002. In need of deliberate inter-school relations in the Northern Cape. South African Journal of Education, 22(2): 95-100. 
Watts M, Ebbutt D 1987. More than the sum of the parts: Research methods in group interviewing. British Educational Research Journal, 13(1): 25-34.

Weber E 2007. Globalization "global" development and teacher work: A research agenda. Review of Educational Research, 77(3): 279-309.

Wenger E 1998. Communities of Practice: Learning Meaning and Identity. New York: Cambridge University Press.

Wengraf T 2001.Qualitative Research Interviewing: Biographic Narrative and Semi-structured Methods. London: Sage Publications.
Wilson V 1997. Focus groups a useful qualitative method for educational research. British Educational Journal, 23(2): 209-224.

Wong LP 2008. Focus group discussion: A tool for health and medical research. Singapore Medical Journal, 49(3): 256.

Yang Y 2014. Principals' transformational leadership in school improvement. International Journal of Educational Management, 28(3): 3.

Yates SJ 2004. Doing Social Science Research. London: Sage Publishing.

Yin RK 2003. Case Study Research: Design and Methods. $3^{\text {rd }}$ Edition. London: Sage Publications. 